\title{
Developing green innovation performance by fostering of organizational knowledge and coopetitive relations
}

\author{
Gema Albort-Morant ${ }^{1,2}$ (D) Antonio Leal-Millán ${ }^{1}$ (iD) \\ Gabriel Cepeda-Carrion $^{1}$ (D) Jörg Henseler ${ }^{3,4}$ JiD
}

Received: 10 February 2017 / Accepted: 27 November 2017

(C) Springer-Verlag GmbH Germany, part of Springer Nature 2017

\begin{abstract}
This study explores the links between knowledge base, relationship learning, and green innovation performance within a coopetitive framework. We posit that green innovation is directly influenced by a broad and deep knowledge base. We also hypothesize that the knowledge base-green innovation performance link is positively mediated by relationship learning (indirect effect). These hypotheses were empirically tested using consistent partial least squares path modeling. A sample of 112 firms from the Spanish automotive components manufacturing sector was used. The mediating effect of relationship learning on the knowledge base-green innovation performance link was observed to be positive and significant. Therefore, managers should build strong relations with stakeholders to assimilate, transfer, and adapt new knowledge and thus enhance green innovation performance.
\end{abstract}

Gema Albort-Morant

galbort@us.es

Antonio Leal-Millán

aleal@us.es

Gabriel Cepeda-Carrion

gabi@us.es

Jörg Henseler

j.henseler@utwente.nl

1 Department of Business Management and Marketing, Universidad de Sevilla, Av. Ramón y

Cajal, 1, 41018 Seville, Spain

2 Centro Universitario San Isidoro, C/ Leonardo Da Vinci, 17B, 41092 Seville, Spain

3 Faculty of Engineering Technology, University of Twente, Postbus 217, 7500 AE Enschede, The Netherlands

4 Nova Information Management School, Universidade Nova de Lisboa, Campus de Campolide, 1070-312 Lisbon, Portugal 
Keywords Knowledge base $\cdot$ Relationship learning $\cdot$ Green innovation performance $\cdot$ Coopetition $\cdot$ Partial least squares

JEL Classification M1 business administration - Q01 sustainable development

\section{Introduction}

In recent decades, heightened concern for environmental issues, stricter regulations, the proliferation of international environmental protection conventions, and greater consumer environmentalism have led companies to develop strategies and policies that are linked to the environment. Green innovation performance measures firms' efforts in terms of environmental management and sustainable practices to assess how well these firms comply with their environmental protection obligations (Chen et al. 2006). Green innovation allows firms to meet stakeholders' demands for maximizing production without harming the ecosystem (Albort-Morant et al. 2016). Thus, environmental issues have become vital to organizations' corporate strategies because of stricter environmental regulations and greater stakeholder demands. Green innovation arises as a corporate reaction to internal changes (cultural shifts, managerial approach, etc.) and external changes (i.e., market trends, stakeholder preferences, normative frameworks, and social demands). Organizations must continually improve their products and processes with agility and speed to attain sustainable competitive advantages.

In light of economic and social globalization, it is hard to imagine how green innovation strategies can effectively occur if they are not at the core of coopetitive (cooperative and competitive) relationships among firms. Ritala et al. (2016, p. 1) report that "in particular, research has shown that coopetition can facilitate innovation among firms, networks, and ecosystems." A paradigmatic example of a coopetitive relationship is the agreement that Toyota and General Motors signed in the 1980s. As reflected in Gast et al. (2015, p. 493), "although being two of the largest competitors on the automobile market, they decided to enter a coopetitive agreement and set up a jointly-owned plant in the US."

Numerous scholars have defined coopetition. Kraus et al. (2017, p. 2) offer a clear, concise definition of coopetition as "the simultaneous competition and collaboration between rival firms operating in the same markets." According to Levy et al. (2003), coopetition combines competitive and collaborative elements. This mixture differentiates coopetition from other kinds of interfirm collaboration. Whatever the purposes and motivations that underlie coopetitive tendencies in partner selection (Kraus et al. 2017), coopetition entails not only risks, but also positive externalities through the development of certain capabilities.

This benefit of coopetition includes the reinforcement and development of knowledge-based capabilities such as knowledge creation, knowledge transfer, and knowledge absorption (Loebecke et al. 1999). In addition, the extent to which companies rely on joint knowledge management activities because of their immersion in coopetitive contexts enhances firms' knowledge base and 
relationship learning capability (Hamel 1991; Levy et al. 2003). In fact, strategic alliances are a pillar of coopetitive strategy because such alliances entail collaborative links with competitors and other stakeholders (Gast et al. 2015). Hamel (1991) affirms that coopetition in the form of strategic alliances with external partners might offer firms the chance to absorb external knowledge and competencies as well as efficiency in terms of knowledge accumulation.

According to the knowledge-based view, knowledge is an essential strategic resource to generate new value creation and competitive advantage (Grant 1996). Their knowledge base gives companies the possibility and ability to understand and use new knowledge to resolve problems, make decisions, and innovate (Ahuja and Katila 2001). Therefore, companies must develop the competencies to build a deep and broad knowledge base that nurtures itself from internal and external knowledge sources. This knowledge base can then reinforce and support the innovation process and the launch of green, innovative products and services.

This sort of innovation may involve a shift in the attitudes of companies that seek to develop close relations with stakeholders and partners (Lettice et al. 2010) and access external knowledge. Therefore, companies must work closely with stakeholders to share knowledge, skills, and a mutual goal to become greener (Chiou et al. 2011). Such efforts are particularly important for SMEs, where knowledge about suppliers, customers, partners, and competitors results from personal contact between organizational members and stakeholders.

For example, in companies that operate through supply chains or projects, developing strong client-supplier relationships is essential for effective, efficient management. To attain and sustain green relationship learning, ensuring cooperation among parties is critical. Therefore, strengthening relationship learning is vital to the firm's knowledge base and the effective attainment of green innovations.

Numerous studies have highlighted the need to reinforce networks and cooperative ties, which are fundamental drivers of organizational success and green innovation performance (Cainelli et al. 2015; De Marchi 2012; Lin and Chang 2009). For instance, Lin and Chang (2009) report the positive impact of green relationship learning on green innovation performance for a sample of Taiwanese manufacturing firms. According to De Marchi's (2012) study of Spanish manufacturing firms, formal cooperation with external partners is more important for green innovation than for other types of innovation. Leal-Millán et al. (2016) showed the positive effects of developing information technology capability and fostering relationship learning on green innovation performance and customer capital. Similarly, Albort-Morant et al. (2016) describe the ties between dynamic capabilities and green innovation performance, introducing relationship learning as a mediating variable.

Building on Albort-Morant et al.'s (2016) study, our goal is to prove that relationship learning mediates the relationship between knowledge base and green innovation performance. We believe that companies with a strong knowledge base need to relate and learn from stakeholders to update their environmental knowledge base and thereby drive their green innovation performance. Therefore, when companies share knowledge with suppliers and customers in supply chain management activities, they improve their knowledge base and capabilities through relationship learning. 
Recently, the cooperation literature has grown, expanding its focus on the progress of core firm competencies and capabilities (Leal-Millán et al. 2017). In SMEs, collaboration with competitors, suppliers, and customers is vital to create effective green innovations because organizations must extend the knowledge creation process beyond the company.

Nevertheless, the mediating role of relationship learning in the link between knowledge base and green innovation performance has been neglected. To the best of our knowledge, no empirical research has been conducted on this topic. This paper responds to these concerns and targets the aforementioned gaps in the literature on knowledge base, green innovation performance, and relationship learning. The green perspective that underlies our analysis constitutes an innovative contribution to the coopetition literature.

According to Devece et al. (2017, p. 3), "the number of published articles on coopetition is increasing rapidly, with a point of inflection around the year 2000. Despite this growth, however, the coopetition literature remains relatively scarce." A major research gap relates to the organizational consequences of coopetition (Gast et al. 2015). This paper also covers this gap by analyzing an issue that has yet remained unexamined in the coopetition literature, namely the role of coopetition in strengthening knowledgebased capabilities and green innovation performance.

Given that knowledge base and green innovation performance are positively related and that there is a need to know which other coopetitive organizational mechanisms/ capabilities managers must activate to improve the success of green innovations, this study addresses the following question: How does the presence of relationship learning (as an ordinary capability) affect the link between knowledge base and green innovation performance? This paper theorizes and examines this central question, evaluating whether relationship learning mediates the knowledge base-green innovation performance link. Thus, we analyze a model that describes the links between knowledge base, relationship learning, and green innovation performance. We shed light on whether and how the deployment of a strong relationship learning capability (in coopetition with a range of stakeholders and competitors) accentuates the effect of a broad and deep knowledge base on industrial firms' green innovation performance.

The study is organized as follows: Sect. 2 presents the primary theoretical foundations, the research model, and the hypothesis. Section 3 describes the empirical analysis of a dataset consisting of data on 112 companies in the Spanish automotive components manufacturing sector (ACMS). Section 4 presents the results of the analysis using consistent partial least squares (PLSc) path modeling, a variancebased structural equation modeling technique. Finally, Sect. 5 discusses the results, implications for research and practice, and future lines of research.

\section{Literature review}

\subsection{Coopetition}

The term coopetition was coined to describe cooperative competition. The essential beliefs of coopetitive organizations have been explained in game theory, a scientific 
field that emerged in 1944 with the publication of John von Neumann and Oskar Morgenstern's book Theory of Games and Economic Behavior. Game theory was subsequently developed through John Forbes Nash's work on non-cooperative games. Coopetition can occur in interorganizational or intraorganizational spheres.

Intrafirm coopetition occurs between individuals or operative divisions or units inside the same company. Drawing upon game theory and social interdependence theory, several studies have explored simultaneous cooperation and competition between departments or operational units - the antecedents of coopetition-and the influence on knowledge sharing behaviors (Loebecke et al. 1999). The concept of "coopetitive knowledge sharing" was developed to explain mechanisms whereby coopetition influences effective knowledge sharing practices in cross-functional teams (Ghobadi and D'Ambra 2012). The core argument is that while organizational teams need to cooperate, they are likely to experience strain due to diverse professional values and conflicting objectives from different cross-functional departments.

At the interfirm level, coopetition happens when companies with certain overlapping interests work together. They collaborate with each other to boost value creation yet compete to attain competitive advantage. Coopetition routinely occurs when firms in the same market work together to explore knowledge and new products while competing to gain market share and exploit knowledge that has been created at different stages of the value chain (Fernandes and Ferreira 2017). For example, the PSA group (Peugeot-Citroën) and the Japanese company Toyota share components for a small car, which is marketed by each company as the Peugeot 107, the Toyota Aygo, and the Citroën C1. This agreement has numerous benefits such as cost cutting, resource complementarity, and knowledge or high-tech transfer.

Coopetition may also involve different companies in a supply chain, as in the ACMS. Despite difficulties and risks such as lack of confidence, a major advantage is the knowledge that results from relationship learning.

In this paper, we assume that coopetition provides the ideal scenario for developing organizational capabilities that are linked to both knowledge base enhancement and relationship learning and that may improve firms' green innovation performance. The theoretical linkages between these three constructs are discussed in the research framework and hypothesis section.

\subsection{Knowledge base}

According to the knowledge-based view of the firm, knowledge is a key strategic resource for companies that aim to generate and maintain sustainable competitive advantages (Grant 1996). Although knowledge is produced and spread across the company, it potentially enhances organizational value by boosting proficiency while enabling better reactions to new, unexpected, or unusual situations. The increasing relevance of knowledge as a fundamental organizational resource has led managers to pay more attention to developing knowledge management strategies. Thus, the knowledge-based view recommends firms to develop, absorb, and apply managerial knowledge to attain superior organizational performance (Nonaka 1994) because knowledge is arguably a firm's most important resource (Spender 1996). 
An organization's current knowledge base establishes its prospects and capabilities to recognize the value of new knowledge and apply it to decision-making, problem solving, or innovation (Ahuja and Katila 2001). Zhou and Wu (2010) report that a firm's present knowledge base (i.e., its knowledge breadth and depth) represents the firm's main source of organizational innovativeness. Knowledge breadth and depth are the two components that shape an organization's knowledge base. They reflect the firm's primary knowledge structures and contents. Knowledge depth refers to the degree of intricacy and sophistication of a firm's knowledge base (Bierly and Chakrabarti 1996). Knowledge depth corresponds to the vertical dimension of knowledge-exclusivity, complexity, and specificity. Knowledge breadth refers to the horizontal dimension of knowledge - the heterogeneity of the firm's knowledge base (Zhou and Li 2012).

Knowledge can be divided into several dimensions: the systemic dimension (data, information, and knowledge), the ontological dimension (individual-social), and the epistemological dimension (explicit-tacit). A firm's knowledge base nurtures itself from a variety of internal and external knowledge sources. Some knowledge is more difficult to manage or articulate. Retaining some knowledge within the company is difficult. Therefore, effectively managing the firm's knowledge base is a valuable way to create and sustain new sources of competitive advantage (Grant and BadenFuller 2004).

\subsection{Relationship learning}

In stakeholder theory and the resource-based view of the firm, interorganizational connections are based on mutual individual stakeholders' contributions to shared value creation (Haslam 2004). Drawing upon these theoretical perspectives, this study examines the concept of relationship learning. In the current socioeconomic context, organizations deliberately share information and knowledge with suppliers, customers, and other partners to mutually enhance their knowledge bases and competencies and thereby support the innovation process.

Our theoretical background primarily builds on the approach of Selnes and Sallis (2003, p. 86), who coined the concept of relationship learning, defining it as "a joint activity in which two parties strive to create more value together than they would create individually or with other partners." Therefore, companies strive to collaborate with specific partners that enable the improvement of future behaviors and increase the benefits that are associated with such relationships. Cheung et al. (2011) denote relationship learning as a joint activity between buyers and suppliers in which two parties share information. According to Selnes and Sallis (2003), relationship learning has three dimensions: information sharing, joint sensemaking, and knowledge integration. We focus on the joint sensemaking dimension of relationship learning. We consider that this dimension most accurately fits the behavior of ACMS firms within supply chain relationships. It is crucial for ACMS firms to build common understanding and joint sensemaking with their primary customers (large automakers). This is consistent with the views of Leal-Millán et al. (2016, p. 448), who state that "organisations in a customer-supplier relationship introduce 
management meetings, face-to-face communications in visit programmes, informal interpersonal networks, task-forces teams and cross-functional teams as instruments to solving operational problems in the relationship, and creating joint learning arenas." Thus, only through these face-to-face meetings and personal relationships between both firms' employees can tacit knowledge (the richest form of knowledge) be effectively shared and assimilated (Nonaka 1994). Accordingly, joint sensemaking is the most critical dimension of relationship learning (Selnes and Sallis 2003).

Normally, the exchange of knowledge between parties in supply chain cooperation represents a relationship-specific component of understanding and cohesion. Nevertheless, the groups might differ in the way they grasp and perceive the same information (i.e., sensemaking). Alternatively, they might lack the right knowledge to make sense of this information. Thus, companies may use an array of mechanisms to foster joint sensemaking (i.e., face-to-face communication during visit programs, management meetings, informal or personal networks, and project-based and cross-functional teams). Such instruments guide firms along their cooperative path, creating joint learning areas and solving the operational problems that are inherent to relationships.

\subsection{Green innovation performance}

Green innovation performance measures the extent to which organizations develop innovations that reduce or minimize environmental damages, impact, and deterioration while optimizing the use of natural resources (Albort-Morant et al. 2016, 2017; Chang and Chen 2013; Chen et al. 2006). As a strategy, green innovation offers great opportunities to meet buyers' requirements while preserving the ecosystem (AlbortMorant et al. 2016, 2017). Customers around the world increasingly seek to buy products and services that are ecological, environmentally conscious, eco-friendly, or green. The "green" tag offers a real incentive for firms to develop nonstop innovation, craft new market opportunities, and comply with new consumer requests, thereby building and enhancing customer capital (Leal-Millán et al. 2016).

To carry out environmental procedures, companies develop new processes, products, technologies, and/or management strategies that are designed to raise effectiveness. We adopt Chen et al.'s (2006, p. 332) definition of green innovation as "hardware or software innovation that is related to green products or processes, including the innovation in technologies that are involved in energy-saving, pollution-prevention, waste recycling, green product designs or corporate environmental management."

Chang (2011) conceptualized green innovation as a particular type of innovation that enables a company to improve its corporate image, develop new markets, and extend its competitive advantage while satisfying stakeholders' environmental protection requests. Likewise, Leenders and Chandra (2013) affirm that green innovation entails product or process innovations that deal with technological development for pollution prevention, recycling, waste reprocessing, energy saving, and eco-efficient design. Hashim et al. (2015) argue that this sort of innovation reduces organizations' environmental footprint by embracing significant shifts in corporate 
strategy, product design methods, productive processes, resource use, and waste treatment procedures. In our research model, we focus on green innovation performance to capture the outcomes of firms' green innovation efforts.

\section{Research framework and hypothesis}

\subsection{The mediating effect of relationship learning on the knowledge base-green innovation performance link in a coopetitive context}

Innovation involves the invention and application of new or novel ideas about products, services, or processes. Nowadays, many firms are pressed to embrace active strategies that address the growing importance of environmental issues. According to Chesbrough (2003), companies should use external and internal ideas to generate successful green innovation processes and products. Accordingly, the starting point of numerous green innovations might be a partner's ideas and proposals (Koc and Ceylan 2007).

Such a starting point might apply to most ACMS companies that are involved in coopetitive networks. Consistent with Dagnino and Padula (2002), simple network coopetition is shaped by coopetition among multiple companies at one level of the value chain. In car manufacturing, buyer-supplier relationships are often under the parallel sourcing, as opposed to sole sourcing, framework (Richardson 1993). Often, parallel buyers (e.g., Renault) choose two or three suppliers, at least one of which is from the internal market (Dagnino and Padula 2002). This relationship structure serves to keep extensive transmission of materials and knowledge about process techniques among the distinct members throughout the supply chain. Commitment to long-term cooperation does not imply the abandonment of competition between suppliers. In fact, Japanese car manufacturers have traditionally trusted multiple suppliers that are entrenched in a multi-tier system more than their American counterparts have.

The key to blending cooperation and competition lies in the firms' inclination to work with suppliers to resolve technical or financial issues, rather than replacing them immediately with alternative sources (i.e., non-switching). ACMS companies may also supply their products (i.e., automotive equipment and components) to different end customers (i.e., large automakers). The tire industry exemplifies network coopetition. An agreement was signed by several key actors in the tire industry. This agreement involved a particular automotive component. Despite remaining fierce rivals, four competitors-Michelin, Goodyear, Pirelli, and Dunlop-jointly designed and commercialized the PAX system, which has been made available in some Renault and Audi automobiles.

A firm's resources and capabilities are among the main sources of competitive advantage and business innovation. Firms' knowledge management and organizational learning strategies are greatly influenced by these firms' knowledge-related resources and capabilities such as technical competencies, technological updates, knowledge bases, and the management and storage of organizational knowhow. Arguably, the main driver of knowledge management is the firm's stock of 
knowledge, which is the set of accumulated knowledge resources and knowledgebased capabilities that the firm has gathered (Leal-Millán et al. 2017).

Knowledge is a key strategic resource for companies that seek to sustain environment-based competitive innovations. Since knowledge is created and shared throughout the company and across different partners, knowledge potentially generates shared value by increasing the ability to react and respond to new, unexpected situations. Growing concerns regarding the importance of knowledge and learning mechanisms and their role as key resources and capabilities has inspired managers to appreciate and build relationships that are based on learning strategies.

Companies that collaborate with stakeholders to develop relationship learning processes might leverage their knowledge bases by retrieving and absorbing pertinent knowledge from clients, suppliers, competitors, and other partners. Therefore, the establishment of strategic alliances, collaborations, or partnerships might effectively improve the basis of green organizational innovativeness through the sharing of complementary sets of resources and capabilities (Cheng 2011). Firms can also use joint ventures, interorganizational networks, R\&D consortium agreements, and sector clusters to become more innovative (Doz et al. 2000). The creation of collaborative networks between organizations and stakeholders may become a crucial step in this development (Bossink 2002).

Therefore, cooperation and knowledge exchange with external agents leads to knowledge generation and absorptive capacity enhancement, which in turn may improve the firm's innovation outcomes and overall performance (Akgun et al. 2007). Firms are urged to develop joint learning-based activities involving their clients, suppliers, intermediaries, and other partners. In these activities, different parties share environmental or green knowledge (De Marchi 2012; Leal-Rodríguez et al. 2013).

In short, developing relationship learning mechanisms should enhance suppliers' understanding of clients' needs, improve customization through green knowledge exchange between client and supplier, and increase the firm's green innovation capacity (Kohtamäki and Partanen 2016; Leal-Millán et al. 2017). Therefore, the presence of these relational learning mechanisms should improve green innovation performance (Fig. 1):

H1 Relationship learning mediates the link between the firm's knowledge base and green innovation performance.

\section{Method}

\subsection{Sample and data collection}

This study examined firms in the innovative, knowledge-intensive Spanish ACMS. We focused on this sector for three reasons. First, the Spanish automotive sector is the second most important in Europe and the eighth worldwide. Nine vehicles manufactures operate in Spain: Ford, Renault, Mercedes, Nissan, Renault, Peugeot, Opel, Seat, and Citroën. The sector's main strengths are high productivity, a highly 


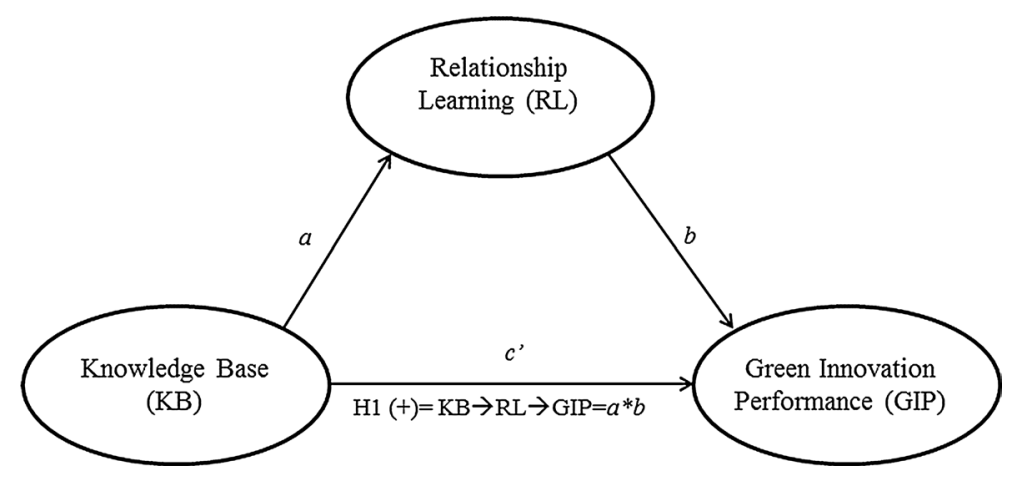

Fig. 1 Research model

qualified labor force, high investment in R\&D, sophisticated machinery, and competitive component and auxiliary industries. Second, this sector is obliged to minimize waste generation (Santini et al. 2011), so companies must comply with strict environmental regulations. Finally, this industry is characterized by a high presence of alliances or cooperative actions between stakeholders. Component manufacturers should provide a service that satisfies the needs of their primary clients (i.e., large vehicle manufacturing firms). For example, component manufacturers can design and produce reused and recycled parts, use recycled materials, reduce residual waste, and limit the use of dangerous or harmful substances in the production process (Gerrard and Kandlikarb 2007).

The sample was collected from a list of firms provided by Sernauto (www.sernauto.es), the Spanish association of automotive components and equipment manufacturers. According to the Sernauto Annual Report (2015), Sernauto's associated companies account for more than $85 \%$ of the sector's revenue and range from SMEs to large national and international groups. Of the 960 companies in this sector, we selected 387 that, according to their corporate reports, have green innovation processes and practices. This study used an offline survey to gather the data.

As a preliminary step in the data collection procedure, we pre-tested the survey using a three-step process. First, we administered the survey questionnaire to expert researchers. Second, we distributed the questionnaire to managers of local companies. After these two rounds, we debriefed respondents and adapted some of the survey items to improve their fit to this study. Lastly, we translated the questionnaire (originally in English) into the language of the research context (Spanish) to aid respondents' understanding.

This survey was distributed following a two-stage process. First, to avoid nonresponse bias, we sent an invitation letter explaining the purpose of the study and guaranteeing that participants' responses would be voluntary, anonymous, and confidential. In addition, we offered respondents an executive summary of the research findings in return for answering the questionnaire accurately. Afterward, we mailed the survey to top executive managers at these firms. We obtained 112 usable surveys (28.94\% response rate). This low response rate might be because respondents 
were top executives. Nevertheless, the low response rate seemed not to be a serious concern following assessment of generalizability using two nonresponse bias tests. We evaluated potential nonresponse bias using a set of t-tests that contrasted early survey responses with late responses in terms of all key constructs in the model. Responding firms were also compared with non-responding firms in terms of size and performance. No significant differences between the two groups were observed. This finding suggests that nonresponse bias was not a problem. Table 1 shows the respondents' demographic characteristics.

\subsection{Measures}

The questionnaire design was based on the extensive literature review in Sect. 2. The questionnaire consisted of previously validated scales, where all item responses were measured on a seven-point Likert scale ranging from 1 (strongly disagree) to 7 (strongly agree). The scale for measuring relationship learning was adapted from Selnes and Sallis (2003). We used the joint sensemaking dimension of relationship learning as a measure because this dimension accurately describes the behavior of stakeholders in the automotive sector.

The knowledge base construct was measured using a seven-item scale that was adapted from Zhou and $\mathrm{Li}$ (2012). This scale divides the knowledge base into two dimensions: knowledge breadth and knowledge depth. Although this construct has two dimensions, several authors such as Leal-Rodríguez et al. (2013) have modeled the construct as a unidimensional measure, indicating that these companies build a knowledge base that is simultaneously broad and deep. Moreover, the effectiveness of a firm's knowledge base requires both breadth and depth, especially in innovation-related activities. In the case of the firm's absorptive capacity, both potential and realized absorptive capacity (Zahra and George 2002) must be used. Similarly, both subsets of knowledge base are equally necessary and complementary to gain knowledge-based competitive advantages.

Table 1 Survey respondents' demographics

\begin{tabular}{lcc}
\hline Characteristic & Number & Percentage (\%) \\
\hline Gender & 98 & 88 \\
Male & 14 & 12 \\
Female & & \\
Age & 7 & 6 \\
30-40 years & 49 & 44 \\
41-50 years & 40 & 36 \\
51-60 years & 16 & 14 \\
Over 60 years & & \\
Size & 83 & 74 \\
Less than 50 employees & 18 & 16 \\
50-249 employees & 11 & 10 \\
More than 250 employees & & \\
\hline
\end{tabular}


Finally, to measure green innovation performance, we adapted Chen et al.'s (2006) eight-item scale. Although Chen et al. (2006) distinguished between green product and process innovation performance, we measured green innovation performance as a unidimensional measure because we assumed that both product and process innovations are equally fundamental for attaining superior green innovation performance. Also, as Chang and Chen (2013) report, most green product innovations in the industrial context require parallel green process innovations. This unidimensional measurement of green innovation performance is consistent with prior studies, which have adopted the same approach (e.g., Chang and Chen 2013; LealRodríguez et al. 2017). Firm size was used as a control variable. Previous studies on green innovation have shown that size affects green innovation propensity, stressing SMEs' difficulties regarding the complexity that is inherent to green innovations and the investments that are required to switch to greener processes and technologies (De Marchi 2012).

\subsection{Data analysis}

Consistent partial least squares (PLSc) path modeling is a variance-based structural equation modeling technique (Dijkstra and Henseler 2015; Henseler et al. 2016). This method allows the combined use of latent variables that represent concepts that are grounded in theory and data from manifest variables. PLSc was used to assess the measurement model (i.e., the reliability and validity of the measures) and to estimate the structural model (i.e., the modeled relationships between constructs).

Use of PLSc was justified for the following reasons (Henseler et al. 2016): First, we used latent variables as composites. Second, the research model had reflective latent variables (Henseler 2017) that were used to define a state where perceived variables were equally dependent upon another variable which was not itself observed. As the model had reflective variables, it was analyzed using the "Mode A consistent" approach. Third, the research model used non-normal data. Fourth, the study consisted of exploratory analysis. We used ADANCO 2.0 software to test the validity and statistical significance of the measurement and structural models, respectively (Henseler and Dijkstra 2015).

\section{Results}

Following Henseler et al. (2016), we assessed the PLSc model in three phases: (1) determining the global model assessment; (2) verifying the reliability/validity of the measurement model; and (3) assessing the significance of the paths (relationships between constructs) within the structural model.

\subsection{Global model}

The global model assessment requires the use of goodness-of-fit measures. These measures are based on means of bootstrap-based tests of the model fit over the least 
Table 2 Goodness of model fit (estimated model)

\begin{tabular}{lll}
\hline Fit measures & Original value & HI95 \\
\hline SRMR & 0.08 & 0.09 \\
$\mathrm{~d}_{\mathrm{ULS}}$ & 0.99 & 1.27 \\
$\mathrm{~d}_{\mathrm{G}}$ & 0.51 & 1.21 \\
\hline
\end{tabular}

Table 3 Goodness of model fit (saturated model)

\begin{tabular}{lll}
\hline Fit measures & Original value & HI95 \\
\hline SRMR & 0.08 & 0.09 \\
$\mathrm{~d}_{\text {ULS }}$ & 0.99 & 1.27 \\
$\mathrm{~d}_{\mathrm{G}}$ & 0.51 & 1.21 \\
\hline
\end{tabular}

squares and the maximum likelihood and the geodesic discrepancy between the empirical and the model-implied correlation matrix (Dijkstra and Henseler 2015). The original SRMR value met the cut-off value that is suggested by $\mathrm{Hu}$ and Bentler (1999). Table 2 shows that all the deviations were insignificant because the $95 \%$ bootstrap quantiles of the value of the three measures were bigger than the original values (Henseler et al. 2016).

\subsection{Measurement model}

Following Henseler et al. (2016), we assessed the exact goodness of fit of the saturated model. The values of SRMR, dULS, and dG were lower than the corresponding HI95 values (Table 3). The evaluation of the measurement model yielded acceptable results. All indicators and dimensions met the requirement of reliability because their outer loadings were greater than 0.707 (Table 4). Only some of the outer loadings were slightly less than this critical value. Nevertheless, they were retained to support the content validity of the scales. Only two items were removed from the knowledge base construct because their outer loadings were low. All second-order reflective (superordinate) constructs (relationship learning and knowledge base) and the first-order construct (green innovation performance) complied with the requisite of construct reliability because their composite reliabilities and Dijkstra-Henseler's indicator (Rho_A) were greater than 0.7. Table 5 shows that all variables had discriminant validity, according to the HTMT criterion (Henseler et al. 2015), thereby providing evidence that green innovation performance, relationship learning, and knowledge base are distinctive constructs.

\subsection{Structural model}

Following Hair et al. (2014), a bootstrapping technique (5000 re-samples) was employed to generate standard errors and t-statistics to assess the statistical significance of the links that were described in the two research models. Table 6 shows 
Table 4 Measurement model: loadings, construct reliability, and discriminant validity

\begin{tabular}{llll}
\hline Construct/dimension/indicator & Outer loadings & $\begin{array}{l}\text { Dijkstra-Hense- } \\
\text { ler's rho (Pa) }\end{array}$ & $\begin{array}{l}\text { Average variance } \\
\text { extracted (AVE) }\end{array}$ \\
\hline Knowledge base $($ KB) & & 0.829 & 0.532 \\
KB1 & 0.916 & & \\
KB2 & 0.426 & & \\
KB3 & 0.223 & & \\
KB4 & 0.554 & & \\
KB5 & 0.761 & & \\
Relationship learning $($ RL) & & & \\
RL1 & 0.963 & & \\
RL3 & 0.915 & & \\
RL3 & 0.853 & & \\
RL4 & 0.956 & & \\
Green innovation performance (GIP) & & & \\
GIP1 & 0.924 & & \\
GIP2 & 0.894 & & \\
GIP3 & 0.896 & & \\
GIP4 & 0.744 & & \\
GIP5 & 0.776 & & \\
GIP6 & 0.921 & & \\
GIP7 & 0.958 & & \\
GIP8 & 0.803 & & \\
\hline
\end{tabular}

the main parameters that were obtained for the model in the structural assessment. The adjusted coefficient of determination $\left(\mathrm{R}^{2}\right)$ was used as the main criterion for the explained variance, which is shown in the dependent construct as path coefficients that are depicted in the models. These results confirm that the structural models had acceptable predictive relevance for the endogenous constructs of relationship learning and green innovation performance.

The model comprised the total link between knowledge base and green innovation performance. Our results provide support for the total relationships between knowledge base and relationship learning $(0.214 * ; 2.110)$, knowledge base and green innovation performance $(0.197 * * * ; 3.787)$, and relationship learning and green innovation performance $(0.620 * * * ; 7.78)$. This case is a necessary but not

Table 5 Measurement model: discriminant validity

\begin{tabular}{llcl}
\hline \multicolumn{4}{l}{ Heterotrait-monotrait ratio of correlations (HTMT) } \\
\hline KB & RL & GIP \\
KB & & & \\
RL & 0.165 & & \\
GIP & 0.305 & 0.659 & \\
\hline
\end{tabular}


Table 6 Structural model results

\begin{tabular}{llll}
\hline & $\begin{array}{l}\text { Original coef- } \\
\text { ficient }\end{array}$ & Model & $95 \%$ confidence intervals \\
\hline & & $\mathrm{R}_{\mathrm{RL}}^{2}=0.037$ & \\
$\mathrm{R}_{\mathrm{GIP}}^{2}=0.465$ & \\
$\mathrm{a}: \mathrm{KB} \rightarrow \mathrm{RL}$ & $0.214 *(2.110)$ & {$[0.047 ; 0.432] \mathrm{Sig}$.} \\
$\mathrm{c}^{\prime}: \mathrm{KB} \rightarrow \mathrm{GIP}$ & 0.329 & $0.197 * * *(3.787)$ & {$[0.191 ; 0.528] \mathrm{Sig}$.} \\
$\mathrm{b}: \mathrm{RL} \rightarrow \mathrm{GIP}$ & 0.619 & $0.620^{* * *}(7.786)$ & {$[0.455 ; 0.763] \mathrm{Sig}$.} \\
$\mathrm{H} 1 \mathrm{~KB} \rightarrow \mathrm{RL} \rightarrow \mathrm{GIP}$ & 0.133 & $0.1329^{*}(2.027)$ & {$[0.0279 ; 0.277] \mathrm{Sig}$.} \\
(Indir. effect) & & & \\
\hline
\end{tabular}

$\mathrm{t}$-values in parentheses; bootstrapping $95 \%$ confidence intervals bias corrected in square brackets (based on $\mathrm{n}=5000$ subsamples)

$n s$ not significant

${ }^{* * *} p<.001, * * p<.01, * p<.05$ (based on $\mathrm{t}(4999)$, one-tailed test $) ; \mathrm{t}(0.05,4999)=1.645, \mathrm{t}(0.01$, 4999) $=2.327, \mathrm{t}(0.001,4999)=3.092$

sufficient condition for the indirect effect of knowledge base on green innovation performance through relationship learning (Nitzl et al. 2016). Consequently, we tested whether $\mathrm{a} \times \mathrm{b}$ was also significant. This model also showed that the indirect effect $\left(\mathrm{H} 1=0.1329^{*} ; 2.027\right)$ was significant.

To estimate the indirect effect of knowledge base on green innovation performance, PLSc analysis provided 95\% bootstrap confidence intervals for the indirect effect. If 0 was absent from the interval for an indirect effect, the indirect relationship differed significantly from zero with a $95 \%$ confidence level. Our study showed partial (complementary) mediation because the indirect and direct effects were significant. This result implies that relationship learning partially mediates the effect of knowledge base on green innovation performance. The results in Table 6 confirm that the structural model was satisfactory.

\section{Discussion and conclusions}

Recent studies have explored the existence of a direct link between knowledge base and green innovation performance (Albort-Morant et al. 2016; Leal-Rodríguez et al. 2013) and between relationship learning and green innovation performance (Cainelli et al. 2015; De Marchi and Grandinetti 2013). The mediating effect of relationship learning on the link between knowledge base and green innovation performance, however, has scarcely been explored. Building on prior studies, this paper presents a model that explores this mediating effect.

The empirical analysis shows that the total and indirect effects of knowledge base on green innovation performance are positive and significant. The structural model supports the hypothesis that a firm's knowledge base positively affects green innovation performance through reconfiguration and enhancement of relationship learning 
capability. The analysis provides evidence of this indirect effect of knowledge base on green innovation performance via relationship learning.

According to these findings, a company's knowledge base affects green innovation performance, but this effect is greater if the company shares and compares information with stakeholders through relationship learning. This study shows that a strong organizational knowledge base and knowledge acquisition and creation through coopetitive relationship learning are vital for firms to achieve high green innovation performance.

This study makes some noteworthy contributions for academics and practitioners. First, it sheds light on the conceptualization of knowledge base, relationship learning, and green innovation performance. Green innovation might become a key variable for researchers and executives because it potentially acts as a catalyst for achieving high organizational performance and attaining competitive advantages. Second, drawing on the knowledge base, relationship learning, and green innovation performance literatures, we propose a research model that explores the mediating link between these constructs. Third, we present the results of empirical hypothesis testing for a sample of 112 Spanish ACMS firms. In addition, this study contributes to the resources and capabilities literature by demonstrating that the existence of competitive advantage (here, effective green innovations) requires not only a set of powerful resources (e.g., a broad and deep knowledge base), but also certain capabilities (e.g., relationship learning) to develop these resources through interorganizational cooperative and competitive relations.

This study has major practical implications for strategic managers of manufacturing firms who seek a green knowledge base to improve green innovation performance. The green innovation performance in these companies is often highly conditioned by prior accumulation of associated knowledge in the knowledge base.

We provide the theoretical and empirical foundations for further analysis of green innovation performance of firms in the ACMS. In a context of close cooperation and competition, ACMS companies can gather interesting information on the latest environmental changes within the sector. Therefore, these companies should establish and strengthen ties with stakeholders, thereby forming a partnership rather than a traditional customer-supplier relationship. Accordingly, knowledge base and relationship learning should be among the key resources and capabilities that are encouraged at the managerial level to achieve better green innovation performance. Our results reveal that fostering a strong relationship learning capability (in coopetition with a broad set of stakeholders and competitors) enhances the effect of a broad and deep knowledge on the green innovation performance of industrial firms.

This study nonetheless has certain limitations. First, although this study provides evidence of causality, the analysis did not test causality itself. Second, the analysis was based on the subjective perceptions of the respondents, and to elicit insights from respondents, a single method was used. Finally, this study was conducted for a single geographic context (Spain) in a single sector (ACMS). Therefore, researchers must be cautious when generalizing these results and conclusions to other settings.

Based on the implications and limitations that can be derived from this study, the following lines of future research would prove interesting. First, scholars should examine the moderating effect of certain managerial variables that we expect to 
influence green innovation performance. Second, scholars should also adopt a longitudinal approach to collect data at different times. Doing so would enable verification of the hypotheses that are captured by our research model. Third, replicating this study in a different geographic context or sector would be helpful to generalize our insights and conclusions. Fourth, the circular relationship between knowledge base and relationship learning should be studied because these two variables may complement one another. Finally, other key drivers of green innovation performance could be incorporated into future research models.

\section{References}

Ahuja G, Katila R (2001) Technological acquisitions and the innovation performance of acquiring firms: a longitudinal study. Strateg Manag J 22(3):197-220

Akgun AE, Keskin H, Byrne JC, Aren S (2007) Emotional and learning capability and their impact on product innovativeness and firm performance. Technovation 27(9):501-513

Albort-Morant G, Leal-Millán A, Cepeda-Carrión G (2016) The antecedents of green innovation performance: a model of learning and capabilities. J Bus Res 69(11):4912-4917

Albort-Morant G, Henseler J, Leal-Millán A, Cepeda-Carrión G (2017) Mapping the field a bibliometric analysis of green innovation. Sustainability 9(6):1011

Bierly P, Chakrabarti A (1996) Generic knowledge strategies in the U.S. pharmaceutical industry. Strateg Manag J 17(1):123-135

Bossink BA (2002) The development of co-innovation strategies: stages and interaction patterns in interfirm innovation. R\&D Manag 32(4):311-320

Cainelli G, De Marchi V, Grandinetti R (2015) Does the development of environmental innovation require different resources? Evidence from Spanish manufacturing firms. J Clean Product 94:211-220

Chang CH (2011) The influence of corporate environmental ethics on competitive advantage: the mediation role of green innovation. J Bus Ethics 104(3):361-370

Chang CH, Chen YS (2013) Green organizational identity and green innovation. Manag Decis 51(5):1056-1070

Chen YS, Lai SB, Wen CT (2006) The influence of green innovation performance on corporate advantage in Taiwan. J Bus Ethics 67(4):331-339

Cheng JH (2011) Inter-organizational relationships and knowledge sharing in green supply chains-moderating by relational benefits and guanxi. Transp Res Part E Logist Transp Rev 47(6):837-849

Chesbrough H (2003) The logic of open innovation: managing intellectual property. California Manag Rev 45(3):33-58

Cheung MS, Myers MB, Mentzer JT (2011) The value of relational learning in global buyer-supplier exchanges: a dyadic perspective and test of the pie-sharing premise. Strateg Manag J 32(10): 1061-1082

Chiou TY, Chan HK, Lettice F, Chung SH (2011) The influence of greening the suppliers and green innovation on environmental performance and competitive advantage in Taiwan. Transp Res Part E Logist Transp Rev 47(6):822-836

Dagnino GB, Padula G (2002). Coopetition strategy: a new kind of interfirm dynamics for value creation. In: Innovative research in management, European Academy of Management (EURAM), second annual conference, Stockholm, vol. 9

De Marchi V (2012) Environmental innovation and R\&D cooperation: empirical evidence from Spanish manufacturing firms. Res Policy 41(3):614-623

De Marchi V, Grandinetti R (2013) Knowledge strategies for environmental innovations: the case of Italian manufacturing firms. J Knowl Manag 17(4):569-582

Devece C, Ribeiro-Soriano DE, Palacios-Marqués D (2017) Coopetition as the new trend in inter-firm alliances: literature review and research patterns. Rev Manag Sci 1-20. https://doi.org/10.1007/ s11846-017-0245-0

Dijkstra TK, Henseler J (2015) Consistent partial least squares path modeling. MIS Q 39(2):297-316 
Doz YL, Olk PM, Ring PS (2000) Formation processes of R\&D consortia: Which path to take? Where does it lead? Strateg Manag J 21(3):239-266

Fernandes C, Ferreira J (2017) Cooperation and coopetition in SME networks: a bibliometric study. In: Peris-Ortiz M, Ferreira JJ (eds) Cooperative and networking strategies in small business. Springer, New York, pp 11-29

Gast J, Filser M, Gundolf K, Kraus S (2015) Coopetition research: towards a better understanding of past trends and future directions. Int J Entrep Small Bus 24(4):492-521

Gerrard J, Kandlikarb M (2007) Is European end-of-life vehicle legislation living up to expectations? Assessing the impact of the ELV Directive on "green" innovation and vehicle recovery. J Clean Prod 15:17-27

Ghobadi S, D'Ambra J (2012) Knowledge sharing in cross-functional teams: a coopetitive model. J Knowl Manag 16(2):285-301

Grant RM (1996) Toward a knowledge-based theory of the firm. Strat Manag J 17(S2):109-122

Grant RM, Baden-Fuller C (2004) A knowledge accessing theory of strategic alliances. J Manag Stud 41(1):61-84

Hair F, Sarstedt J, Hopkins ML, Kuppelwieser GV (2014) Partial least squares structural equation modeling (PLS-SEM): an emerging tool in business research. Eur Bus Rev 26(2):106-121

Hamel G (1991) Competition for competence and interpartner learning within international strategic alliances. Strateg Manag J 12(S1):83-103

Hashim R, Bock AJ, Cooper S (2015) The relationship between absorptive capacity and green innovation. World Acad Sci Eng Tech 9(4):1065-1072

Haslam N (2004) Relational models theory: a contemporary overview. Laurence Erlbaum Associates, Mahwah

Henseler J (2017) Bridging design and behavioral research with variance-based structural equation modeling. J Advert. https://doi.org/10.1080/00913367.2017.1281780

Henseler J, Dijkstra TK (2015) ADANCO 2.0. Composite modeling, Kleve

Henseler J, Ringle CM, Sarstedt M (2015) A new criterion for assessing discriminant validity in variance-based structural equation modeling. J Acad Mark Sci 43(1):115-135

Henseler J, Hubona G, Ray PA (2016) Using PLS path modeling in new technology research: updated guidelines. Ind Manag Data Syst 116(1):2-20

Hu LT, Bentler PM (1999) Cutoff criteria for fit indexes in covariance structure analysis: conventional criteria versus new alternatives. Struct Equ Model Multidiscip J 6(1):1-55

Koc T, Ceylan C (2007) Factors impacting the innovative capacity in large-scale companies. Technovation 27(3):105-114

Kohtamäki M, Partanen J (2016) Co-creating value from knowledge-intensive business services in manufacturing firms: the moderating role of relationship learning in supplier-customer interactions. J Bus Res 69(7):2498-2506

Kraus S, Meier F, Niemand T, Bouncken RB, Ritala P (2017) In search for the ideal coopetition partner: an experimental study. Rev Manag Sci. https://doi.org/10.1007/s11846-017-0237-0

Leal-Millán A, Roldán JL, Leal-Rodríguez AL, Ortega-Gutiérrez J (2016) IT and relationship learning in networks as drivers of green innovation and customer capital: evidence from the automobile sector. J Knowl Manag 20(3):1-22

Leal-Millán A, Albort-Morant G, Leal-Rodríguez A, Ariza-Montes A (2017) Relationship learning strategy as a mechanism of network and the effectiveness of green innovation. In: Peris-Ortiz M, Ferreira JJ (eds) Cooperative and networking strategies in small business. Springer, New York, pp 81-95

Leal-Rodríguez AL, Roldán JL, Leal AG, Ortega-Gutiérrez J (2013) Knowledge management, relational learning, and the effectiveness of innovation outcomes. Serv Ind J 33(13):1294-1311

Leal-Rodríguez AL, Ariza-Montes AJ, Morales-Fernández E, Albort-Morant G (2017) Green innovation, indeed a cornerstone in linking market requests and business performance. Evidence from the Spanish automotive components industry. Technol Forecast Soc Chang. https://doi.org/10.1016/j. techfore.2017.07.021 (in press)

Leenders MA, Chandra Y (2013) Antecedents and consequences of green innovation in the wine industry: the role of channel structure. Technol Anal Strateg Manag 25(2):203-218

Lettice F, Wyatt C, Evans S (2010) Buyer-supplier partnerships for product design and development in the automotive sector: who invests, in what and when? Int J Product Econ 127:309-319

Levy M, Loebbecke C, Powell P (2003) SMEs, co-opetition and knowledge sharing: the role of information systems. Eur J Inf Syst 12(1):3-17 
Lin MJJ, Chang CH (2009) The positive effect of green relationship learning on green innovation performance: the mediation effect of corporate environmental ethics. In: PICMET'09-2009 Portland international conference on management of engineering \& technology. IEEE, pp. 2341-2348

Loebecke C, Van Fenema P, Powell P (1999) Coopetition and knowledge transfer. ACM SIGMIS Database Special Issue Inf Syst Curr Issues Future Chang 30(2):14-25

Nitzl C, Roldán JL, Cepeda Carrión G (2016) Mediation analysis in partial least squares path modeling: helping researchers discuss more sophisticated models. Ind Manag Data Syst 116(9):1849-1864. https://doi.org/10.1108/IMDS-07-2015-0302

Nonaka I (1994) A dynamic theory of organizational knowledge creation. Org Sci 5(1):4-33

Richardson J (1993) Restructuring supplier relationships in US manufacturing for improved quality. Manag Int Rev, MIR, pp 53-67

Ritala P, Kraus S, Bouncken RB (2016) Introduction to coopetition and innovation: contemporary topics and future research opportunities. Int J Tech Manag 71(1-2):1-9

Santini A, Morselli L, Passarini F, Vassura I, Di Carlo S, Bonino F (2011) End-of-Life vehicles management: Italian material and energy recovery efficiency. Waste Manag 31(3):489-494

Selnes F, Sallis J (2003) Promoting relationship learning. J Mark 67(1):80-95

Sernauto. Annual Report (2015) http://www.sernauto.es/images/memorias_sernauto/2015/

Spender JC (1996) Making knowledge the basis of a dynamic theory of the firm. Strateg Manag J $17: 45-63$

Zahra SA, George G (2002) Absorptive capacity: A review, reconceptualization, and extension. Acad Manag Rev 27(2):185-203

Zhou KZ, Wu F (2010) Technological capability, strategic flexibility, and product innovation. Strateg Manag J 31(5):547-561

Zhou KZ, Li CB (2012) How knowledge affects radical innovation: knowledge base, market knowledge acquisition, and internal knowledge sharing. Strateg Manag J 33(9):1090-1102 